\title{
Influence of neurological level of injury in bones, muscles, and fat in paraplegia
}

\author{
Yannis Dionyssiotis, MD, PhD; ${ }^{1 *}$ George P. Lyritis, MD, PhD; ${ }^{2}$ Nikolaos Papaioannou, MD, PhD; ${ }^{2}$ Panagiotis \\ Papagelopoulos, MD, PhD; ${ }^{2}$ Thomas Thomaides, $\mathrm{MD}, \mathbf{P h D}^{3}$ \\ ${ }^{1}$ Rehabilitation Department, General Hospital of Rhodes, Rhodes, Greece; ${ }^{2}$ Laboratory for Research of the Musculoskeletal \\ System, University of Athens, Kifissia, Greece; ${ }^{3}$ Neurologic Department, Red Cross Hospital, Athens, Greece
}

\begin{abstract}
To investigate the influence of the neurological level of injury in bone mineral content (BMC) and mechanical properties, lean mass (LM), and fat mass (FM) among paraplegics with a similar duration of paralysis (DOP), we separated 30 paraplegics into group A (15 men, high-level paraplegia) and group B (15 men, low-level paraplegia) and compared them with group C (33 men, nondisabled). In all subjects, we measured stress-strain index (SSI) at $14 \%\left(\mathrm{SSI}_{2}\right)$ and $38 \%\left(\mathrm{SSI}_{3}\right)$ of the tibia length and the difference between them using peripheral quantitative computed tomography (XCT 3000 [Stratec Medizintechnik, Pforzheim, Germany]) and lower-limb BMC, LM, and FM (g) using whole-body dual-energy X-ray absorptiometry (Norland XR-36 [Norland Medical Systems, Inc; Fort Atkinson, Wisconsin]). Bone strength parameters, BMC, and LM were statistically decreased, but we found no difference in paraplegic FM compared with group $\mathrm{C}$. We found a correlation between the DOP and the difference between $\mathrm{SSI}_{3}$ and $\mathrm{SSI}_{2}$ in group $\mathrm{B}(r=0.53, p=$ 0.03 and $r=0.5, p=0.04$, respectively). We correlated DOP with FM in group A's lower limbs $(r=0.5, p=0.05)$. Because of the nonsignificant DOP, the groups with paraplegia act differently in tibia mechanical properties and lower-limb body composition.
\end{abstract}

Key words: bone, bone mineral content, bone strength, dualenergy X-ray absorptiometry, fat mass, lean mass, lower limb, men, paraplegia, peripheral quantitative computed tomography.

\section{INTRODUCTION}

The effects of spinal cord injury (SCI) on bone in paralyzed body areas are well documented [1-3]. Additional studies have shown that bone loss and deterioration of body composition are more severe in the sublesional regions of subjects with SCI and tetraplegics than in those of paraplegics [2-4]. The duration of paralysis (DOP) was inversely related to bone and muscle loss as well as fat gain in paraplegics [5-9]. Clinical studies also indicated that neurological injuries are associated with the development of rapid and severe osteoporosis that is not only due to compromised biomechanical function but could also originate in the central nervous system [10-13]. However, the importance of neurological level of injury (NLOI) and the influence of the DOP among patients with paraplegia grouped by high and low NLOI are inadequately investigated concerning bone mineral content (BMC), lean mass (LM), fat mass (FM), and the mechanical properties of bone. Peripheral

\footnotetext{
Abbreviations: ANOVA = analysis of variance, ASIA = American Spinal Injury Association, $\mathrm{BMC}=$ bone mineral content, $\mathrm{BMI}=$ body mass index, DEXA = dual-energy X-ray absorptiometry, DOP = duration of paralysis, FM = fat mass, $\mathrm{LM}$ = lean mass, NLOI = neurological level of injury, pQCT = peripheral quantitative computed tomography, SCI = spinal cord injury, SD = standard deviation, SNS = sympathetic nervous system, SSI $=$ stress-strain index, SSI $_{2}=$ SSI at $14 \%$ of tibia length, $\mathrm{SSI}_{3}=\mathrm{SSI}$ at $38 \%$ of tibia length, $\mathrm{T}=$ thoracic, $\mathrm{SSI}_{3-2}=$ difference between $\mathrm{SSI}_{3}$ and $\mathrm{SSI}_{2}$.

* Address all correspondence to Yannis Dionyssiotis, MD, PhD; Rehabilitation Department, General Hospital of Rhodes, Agioi Apostoloi, Rhodes, Dodecanese, 85100, Greece; +30-694-6469759; fax: +30-224-1066410.

Email: yannis dionyssiotis@hotmail.com

DOI:10.1682/JRRD.2008.12.0163
} 
quantitative computed tomography (pQCT) allows the noninvasive evaluation of bone strength parameters of long bones [14]. Dual-energy X-ray absorptiometry (DEXA [XR-36; Norland Medical Systems, Inc; Fort Atkinson, Wisconsin]) measures body composition precisely and accurately; gives a regional distribution of BMC, FM, and LM; and offers an alternative way of measuring body composition [15].

The aim of our present study was (1) to compare possible changes in the tibia's mechanical strength to the nondisabled tibia and (2) to investigate lower-limb BMC, $\mathrm{LM}$, and FM in relation to NLOI and DOP in patients with paraplegia above thoracic (T) 7 NLOI versus patients with paraplegia with NLOI between T7 and T12.

\section{MATERIALS AND METHODS}

\section{Demographics}

We included 30 subjects with complete chronic paraplegia (an absence of sensory or motor function below the NLOI, including the lowest sacral segment) in comparison with 33 nondisabled subjects. We considered neurological stabilization and the absence of spinal shock to be chronic paraplegia (range: 1.5-22.0 yr). We separated the subjects as follows (values expressed as mean \pm standard deviation [SD]): group A (15 males with high-level paraplegia [T4-T7 NLOI] (range: 1.5-22.0 yr), aged $32.88 \pm 15.60 \mathrm{yr}$, DOP $5.97 \pm 5.90 \mathrm{yr}$ ) and group B (15 males with low-level paraplegia [T8-T12 NLOI] (range: 1.5-20.0 yr), aged $39.47 \pm 13.81$ yr, DOP $5.65 \pm 5.80$ yr). We recruited the control group (group C) from volunteers of similar age, height, and weight to the subjects with paraplegia. We considered group $\mathrm{C}$ to be nondisabled after a physical examination and comprehensive medical history review if they were free of any previous fracture, endocrine or metabolic bone disease, malignancy, drug abuse, alcoholism, and hepatic or renal disorders.

\section{Methods}

We recruited volunteers with paraplegia from the Greek Paraplegic Society using an announcement for participation in clinical research at Athens University. We designed the protocol according to the Declaration of Helsinki and all subjects gave written informed consent. We certify that we followed all applicable institutional and governmental regulations concerning the ethical use of human volunteers during the course of this research.

Subjects with paraplegia underwent a physical examination by a rehabilitation specialist (Dr. Dionyssiotis), who defined the NLOI according to the international standards of the American Spinal Injury Association (ASIA) protocol and the ASIA Impairment Scale [16]. We recorded anthropometric factors for all subjects, including age, height, weight, and body mass index (BMI) (Table 1), and clinical parameters for subjects with paraplegia, including age at injury, DOP, and NLOI, according to a questionnaire designed for this protocol [5]. None of the subjects with SCI was younger than 25 years at the time of examination or experienced heterotopic ossifications. We also excluded subjects with chronic use of drugs that promote bone loss and with coexisting diseases that impair bone tissue.

We assessed spasticity using the Ashworth Scale [17]. In the present study, all subjects with paraplegia were above T12 NLOI with various degrees of spasticity according to the Ashworth Scale. We examined all subjects using pQCT. We performed measurements with an XCT-3000 (Stratec Medizintechnik; Pforzheim, Germany) at the left tibia (one leg study) [14]. We used the distal end of the tibia as an anatomical marker. We derived the stress-strain index (SSI) parameter, a bone strength estimator, from the section modulus and the volumetric density of the cortical area at $14\left(\mathrm{SSI}_{2}\right)$ and 38 percent $\left(\mathrm{SSI}_{3}\right)$ of the tibia length proximal to the distal end of the tibia [18]. In subjects with paraplegia, we measured height of participants while in supine position before the examination and weight while they were in seated position in the wheelchair

Table 1.

Anthropometric data of subjects.

\begin{tabular}{|c|c|c|c|c|}
\hline \multirow[b]{2}{*}{ Parameter } & \multicolumn{3}{|c|}{ Groups (Mean \pm SD) } & \multirow[b]{2}{*}{ ANOVA $p$-Value } \\
\hline & Control $(n=33)$ & $\begin{array}{c}\text { High-Level } \\
\text { Paraplegia }(n=15)\end{array}$ & $\begin{array}{c}\text { Low-Level } \\
\text { Paraplegia }(n=15)\end{array}$ & \\
\hline$\overline{\text { Age (yr) }}$ & $37 \pm 19$ & $35 \pm 14$ & $43 \pm 16$ & 0.37 \\
\hline Weight (kg) & $81.36 \pm 13.00$ & $76.67 \pm 17.12$ & $76.67 \pm 17.12$ & 0.08 \\
\hline Height (m) & $1.76 \pm 0.05$ & $1.77 \pm 0.06$ & $1.75 \pm 0.10$ & 0.68 \\
\hline $\mathrm{BMI}\left(\mathrm{kg} / \mathrm{m}^{2}\right)$ & $26.12 \pm 5.00$ & $22.94 \pm 2.21$ & $24.86 \pm 3.50$ & 0.02 \\
\hline
\end{tabular}


(after subtracting the wheelchair's weight). We also calculated the BMI (weight $[\mathrm{kg}] / \mathrm{height}^{2}[\mathrm{~m}]$ ) of each subject. We also examined all subjects using DEXA to estimate regional lower-limb BMC, LM, and FM (g). The coefficient of variation was $2.3 \pm 0.9$ percent for total FM and $2.1 \pm 0.4$ percent for total LM. The basic principles of pQCT and DEXA are described elsewhere [14,19-20].

\section{Statistical Analysis}

All variables are represented by the number of subjects $(n)$ and mean value \pm SD. We performed comparisons of variables among the groups using one-factor analysis of variance (ANOVA) with no repeated measurements model (one-way ANOVA) and Bonferroni test for pair-wise comparisons. We performed comparisons of variables among groups with paraplegia using the analysis of covariance model, controlling for age at injury and DOP, respectively. All tests are two-sided; we defined $p<0.05$ as significant. We performed all data analysis using SPSS version 10.0 (SPSS, Inc; Chicago, Illinois).

\section{RESULTS}

BMI values for the groups with paraplegia were statistically lower $(p=0.02)$ than group $\mathrm{C}$. $\mathrm{SSI}_{2}$ decreased by 14.45 and 24.66 percent in groups $\mathrm{A}$ and $\mathrm{B}$, respectively ( $p=0.001$ ), while $\mathrm{SSI}_{3}$ decreased by 19.08 and 17.16 percent $(p=0.001)$ compared with group C (Table 2). Figures 1 and 2 depict the linear and logarithmic correlations between $\mathrm{SSI}_{2}$ and DOP and the best-fit equations in both groups with paraplegia. The correlation between $\mathrm{SSI}_{2}$ and DOP was negatively high in both groups with paraplegia together and separately (Table 3 ). However, we found a similar correlation in only group A between $\mathrm{SSI}_{3}$ and DOP (Table 3). Figures $\mathbf{3}$ and $\mathbf{4}$ depict the linear cor- relations and the best-fit equations at $\mathrm{SSI}_{3}$ for both groups with paraplegia. According to these findings, we calculated the difference between $\mathrm{SSI}_{3}$ and $\mathrm{SSI}_{2}\left(\mathrm{SSI}_{3-2}\right.$ $\left[\mathrm{SSI}_{3}-\mathrm{SSI}_{2}\right]$ ) between the groups with paraplegia. Comparison of the mean $\mathrm{SSI}_{3-2}$ of the groups with paraplegia was statistically significant ( $p=0.05$ ) versus group C, but not between groups with paraplegia $(p=0.55)$. Evaluating further correlations and $p$-values between mean $\mathrm{SSI}_{3-2}$ and clinical parameters, we found a strong correlation with the DOP in group B $(r=0.534, p=0.03)$. On the contrary, we found no significant correlation in group A $(r=-0.178, p=0.5)$ (Table 4).

We observed a statistically significant reduction in lower limbs of both groups with paraplegia in comparison with group C in BMC (886 \pm 178 vs 1,214 $\pm 149, p<$ $0.001)$ and $\mathrm{LM}(11,094 \pm 2,174$ vs 19,693 $\pm 3,242, p<$ $0.001)$. However, we found no difference in FM between groups $\mathrm{A}$ and $\mathrm{B}$ and group $\mathrm{C}$ and in the above parameters after analysis according to NLOI between the groups with paraplegia. Table 5 presents the values.

We found the lower-limb BMC to be negative when correlated with the DOP in both groups with paraplegia ( $r=-0.46, p=0.01$ ), but according to the NLOI, we found this to be due to the strong correlation with group A $(r=-0.658, p=0.01)$ (Table 4). DOP was strongly correlated with FM in group A's lower limbs ( $r=0.5, p=$ 0.05). We found no significant relationship between the intensity of bone loss and spasticity (data not shown).

\section{DISCUSSION}

We found BMI values to be statistically reduced in both groups with paraplegia compared with group C. Bone strength parameters, BMC, and LM were statistically decreased, but we found no difference in FM compared

Table 2.

Peripheral quantitative computed tomography (pQCT) parameters of subjects.

\begin{tabular}{|c|c|c|c|c|c|c|c|}
\hline \multirow[b]{2}{*}{$\begin{array}{c}\text { Tibia } \\
\text { Point } \\
(\%)\end{array}$} & \multirow[b]{2}{*}{$\begin{array}{c}\text { Bone } \\
\text { Parameter }\end{array}$} & \multicolumn{3}{|c|}{ Groups (Mean \pm SD) } & \multicolumn{2}{|c|}{ Difference Between Groups (\%) } & \multirow[b]{2}{*}{$\begin{array}{l}\text { ANOVA } \\
p \text {-Value }\end{array}$} \\
\hline & & Control $(n=33)$ & $\begin{array}{c}\text { High-Level } \\
\text { Paraplegia }(n=15)\end{array}$ & $\begin{array}{c}\text { Low-Level } \\
\text { Paraplegia }(n=15)\end{array}$ & $\begin{array}{l}\text { Control and } \\
\text { High-Level } \\
\text { Paraplegia }\end{array}$ & $\begin{array}{l}\text { Control and } \\
\text { Low-Level } \\
\text { Paraplegia }\end{array}$ & \\
\hline 14 & $\mathrm{SSI}_{2}$ & $2,128.51 \pm 179.35$ & $1,820.84 \pm 387.16$ & $1,603.64 \pm 245.53^{*}$ & -14.45 & -24.66 & 0.009 \\
\hline 38 & $\mathrm{SSI}_{3}$ & $2,318.64 \pm 156.95$ & $1,876.14 \pm 240.31^{\dagger}$ & $1,920.84 \pm 141.57^{\dagger}$ & -19.08 & -17.16 & 0.003 \\
\hline $\begin{array}{l}{ }^{*} p \text {-val } \\
{ }^{\dagger} p \text {-val } \\
\text { Note: } \\
\text { ANO }\end{array}$ & $\begin{array}{l}05 . \\
5 . \\
\text { oni tests } \\
\text { alysis of }\end{array}$ & $\begin{array}{l}\text { trol group versus } \\
\text { ce, } \mathrm{SD}=\text { standard }\end{array}$ & $\begin{array}{l}\text { evel paraplegic grou } \\
\text { ion, } \mathrm{SSI}_{2}=\text { stress-st }\end{array}$ & $\begin{array}{l}\text { versus low-level pa } \\
\text { dex at } 14 \% \text { of tibia }\end{array}$ & $\begin{array}{l}\text { up. } \\
=\text { stress-stri }\end{array}$ & 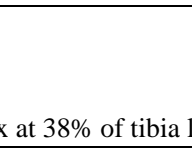 & \\
\hline
\end{tabular}






Figure 1.

We found linear correlation between stress-strain index (SSI) at $14 \%$ of tibia length $\left(\mathrm{SSI}_{2}\right)$ and duration of paralysis (DOP) in group with highlevel paraplegia (range: 1.5-22.0 yr) to best fit our data. Decay equations refer to best-fit SSI data of subjects with paraplegia regarding tibia. $r^{2}=$ goodness of fit of equation (Pearson partial correlation squared), $x=\mathrm{DOP}$ in years ( $x$-axis), $y=\mathrm{SSI}_{2}$ in $\mathrm{mm}^{3}$ ( $y$-axis).

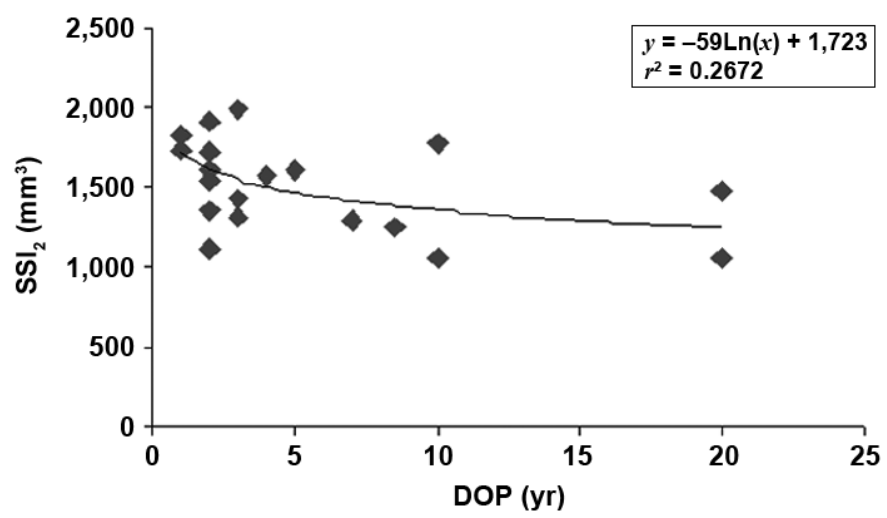

Figure 2.

We found logarithmic correlation between stress-strain index (SSI) at $14 \%$ of tibia length $\left(\mathrm{SSI}_{2}\right)$ and duration of paralysis (DOP) in group with low-level paraplegia (range: 1.5-20.0 yr) to best fit our data. Decay equations refer to best-fit SSI data of subjects with paraplegia regarding tibia. $\operatorname{Ln}(x)=$ logarithmic of $x, r^{2}=$ goodness of fit of equation (Pearson partial correlation squared), $x=\mathrm{DOP}$ in years ( $x$-axis), $y=\mathrm{SSI}_{2}$ in $\mathrm{mm}^{3}$ (y-axis).

with group C. The correlation of BMI with FM was statistically significant in groups $\mathrm{B}$ and $\mathrm{C}$. In a correlation between DOP and BMI, we found $\mathrm{SSI}_{3-2}$ in group $\mathrm{B}$ and between BMC and FM in group A.

BMI values in all subjects were below the BMI signifying obesity (BMI > 27.8) [21]. Furthermore, in both groups with paraplegia we found lower values of BMI than in group C. BMI is a value that relates body weight to body
Table 3.

Correlation and statistical significance in total and within paraplegic groups between duration of paralysis (DOP), $\mathrm{SSI}_{2}$ (stress-strain index at $14 \%$ of tibia length), and $\mathrm{SSI}_{3}$ (stress-strain index at $38 \%$ of tibia length).

\begin{tabular}{ccccc}
\hline \multirow{2}{*}{$\begin{array}{c}\text { pQCT } \\
\text { Variables }\end{array}$} & DOP & \multicolumn{2}{c}{ Groups with Paraplegia } & Tigh-Level \\
\cline { 3 - 4 } & & $\begin{array}{c}\text { Low-Level } \\
(\boldsymbol{n}=\mathbf{1 5})\end{array}$ & $\begin{array}{c}\text { Total } \\
(\boldsymbol{n}=\mathbf{n}=\mathbf{1 5})\end{array}$ \\
\hline $\mathrm{SSI}_{2}$ & $r$ & -0.419 & -0.473 & -0.423 \\
& $p$ & 0.074 & 0.041 & 0.008 \\
$\mathrm{SSI}_{3}$ & $r$ & -0.475 & 0.097 & -0.266 \\
& $p$ & 0.040 & 0.692 & 0.106 \\
\hline
\end{tabular}

Note: Data are presented as correlation coefficients $(r)$.

$p=0.05$ (we defined $p<0.05$ as significant), $\mathrm{pQCT}=$ peripheral quantitative computed tomography, $r \geq 0.4$ medium $(r)>0.6$ strong.

size and does not distinguish between subjects' component of weight (LM and FM). Studies in the literature have proven that FM and body fat percent are greater in paraplegics [8-9]. In a former study, we show that the values of FM in total body composition of a subject with paraplegia compared with a control subject (using whole-body DEXA) were increased. We found BMI to be related to FM in all groups; however, after analysis according to the NLOI, only group B showed significant correlation between BMI and FM. Group B had more FM at any given BMI value than group C [9]. Spungen et al. and Dionyssiotis et al. also found a relationship between total body fat percent and BMI for a SCI and control group, but our finding that the correlation depends on the values of the groups with low-level paraplegia is new [8-9]. An explanation may lie in the specific alterations to body composition of patients with paraplegia and the effect of factors such as immobilization, damage to the sympathetic nervous system (SNS), and hormonal status. Measuring fat with BMI in subjects with chronic paraplegia is not enough to determine a subject's body fat percentage. According to our results, the reduced BMI in the groups with paraplegia is the result of a reduced $\mathrm{LM}$.

According to Spungen et al., the predominant finding regarding bone in subjects with SCI is a large loss during the first year of injury due to disuse osteoporosis, predisposing the subject to an increased prevalence of fractures [8]. Biering-Sørensen et al. demonstrated an ongoing demineralization in the tibia 3 years after trauma [3]. Bauman et al. reported DOP-related bone loss in the lower limbs of monozygotic twins with chronic paraplegia in comparison with their nondisabled cotwins [22]. The results of the 


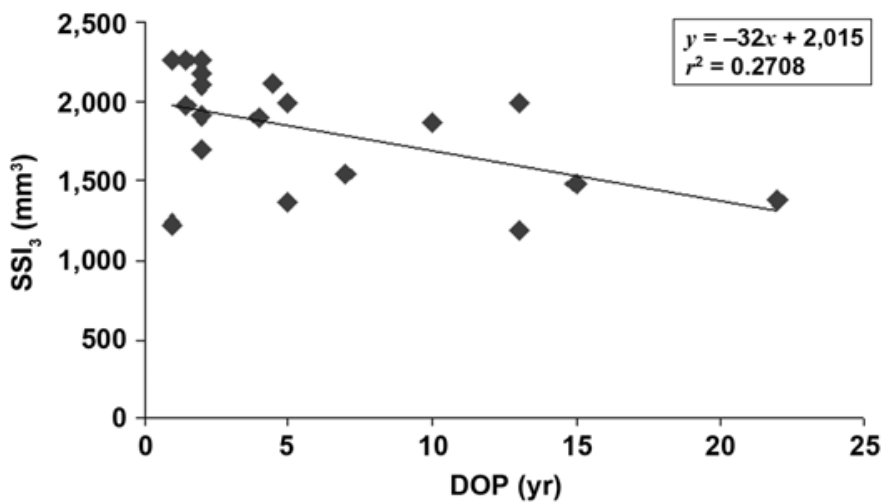

Figure 3.

We found linear correlation between stress-strain index (SSI) at 38\% of tibia length $\left(\mathrm{SSI}_{3}\right)$ and duration of paralysis (DOP) in group with highlevel paraplegia (range: 1.5-22.0 yr) to best fit our data. Decay equations refer to best-fit SSI data of subjects with paraplegia regarding tibia. $r^{2}=$ goodness of fit of equation (Pearson partial correlation squared), $x=\mathrm{DOP}$ in years ( $x$-axis), $y=\mathrm{SSI}_{3}$ in $\mathrm{mm}^{3}$ ( $y$-axis).

comparison between all groups in this study suggest a reduction of lower-leg BMC in subjects with paraplegia independent of the NLOI. BMC in the lower limbs negatively correlated with the DOP in the groups with paraplegia, but after investigating according to the NLOI, we found this correlation to be due to the strong correlation of group A's lower-limb BMC with DOP, meaning that the NLOI determines the extent of bone loss. SSI is an important validated biomechanical strength bone parameter because it is related to bone breaking force, an explanation of why people with chronic SCI are prone to bone fractures [23]. A recent publication found different DOP until steady state for different parameter and scan sites [24]. Based on previously published cross-sectional data from a large number of subjects with paraplegia and tetraplegia [7], Frotzler et al. performed all statistical analyses of tibial and femoral bone data, including only subjects with a lesion duration of at least the time to reach bone steady state $(t)$ for each particular bone parameter calculated from bone measurements at $t 0$ [24]. They chose the cutoff point of 8 years because this was the maximum time required for the femur and tibia to reach the new steady state [7]. This was not the case in our study. Instead, we cross-section analyzed a more homogenous sample of subjects. We did not include tetraplegics or subjects with flaccid paralysis, and we performed the analysis with mean DOP \pm SD (5.65 \pm 5.80 yr vs $12.0 \pm 10.8$ yr [7]). Only $\mathrm{SSI}_{3}$ in group $\mathrm{B}$ did not depend on the DOP, whereas $\mathrm{SSI}_{3}$ in group A and $\mathrm{SSI}_{2}$ in both groups with paraplegia

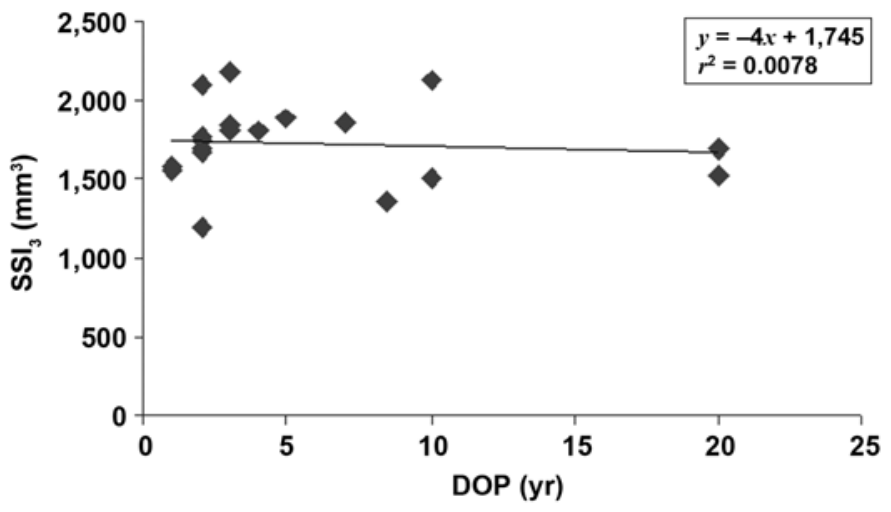

Figure 4.

We found linear correlation between stress-strain index (SSI) at 38\% of tibia length $\left(\mathrm{SSI}_{3}\right)$ and duration of paralysis (DOP) in group with lowlevel paraplegia (range: 1.5-20.0 yr) to best fit our data. Decay equations refer to best-fit SSI data of subjects with paraplegia regarding tibia. $r^{2}=$ goodness of fit of equation (Pearson partial correlation squared), $x=$ DOP in years ( $x$-axis), $y=\mathrm{SSI}_{3}$ in $\mathrm{mm}^{3}$ ( $y$-axis).

depended on the DOP. $\mathrm{SSI}_{3}$ is a value measured in the bone shaft at 38 percent of the tibia length, and according to Eser et al., the cortical wall of the long bones of the paralyzed lower limbs thins but is no less dense (except for a transient decrease during increased intracortical remodeling during the first 5 years after injury), and reaches a new steady state at a higher relative level in the diaphyses than in the epiphyses [7]. Together with the finding that the $\mathrm{SSI}_{3}$ and $\mathrm{BMC}$ in group $\mathrm{B}$ were decreased compared with group $\mathrm{C}$ means that this parameter was already in a steady state.

The strong correlation of $\mathrm{SSI}_{3-2}$ with DOP in group $B$ could not be easily explained because of the similar paralytic effect on bone in both groups with paraplegia despite the nonsignificant DOP between them. This difference could possibly be a result of the higher incidence of standing in group $\mathrm{B}$ and a direct effect of loading on the mechanical parameters of the lower tibia. Paraplegics stand using various devices, long leg braces, and standing frames, although some lose their motivation to use such devices over age. According to DOP, the two groups with paraplegia have different mechanical properties of the tibia. All subjects of both paraplegic groups were in chronic stage which suggests that not only the mechanical (forces-standing) but also the neurogenic factor seems to coexist as an influential regulator in osteoporosis during paralysis. The recent scientific finding of a sympathetic innervation of bone tissue and its role in the regulation of bone remodeling is of major interest in situations where 
Table 4.

$p$-Value and correlation between duration of paralysis (DOP), difference between stress-strain index at 38 and 14 percent of tibia length $\left(\mathrm{SSI}_{3-2}\right)$, and lower-limb bone mineral content (BMC) parameters in paraplegic groups.

\begin{tabular}{lcccc}
\hline Parameter & DOP & \multicolumn{2}{c}{ Groups with Paraplegia } & Total \\
\cline { 3 - 4 } & & $\begin{array}{c}\text { High-Level } \\
(\boldsymbol{n}=\mathbf{1 5})\end{array}$ & $\begin{array}{c}\text { Low-Level } \\
(\boldsymbol{n}=\mathbf{1 5})\end{array}$ & \\
\hline Lower-Limb & $r$ & -0.658 & -0.140 & -0.460 \\
BMC & $p$ & 0.006 & 0.617 & 0.009 \\
SSI $_{3-2}$ & $r$ & -0.178 & 0.534 & 0.071 \\
& $p$ & 0.495 & 0.027 & 0.688 \\
\hline
\end{tabular}

Note: Data are presented as correlation coefficients $(r)$.

$p=0.05$ (we defined $p<0.05$ as significant), $r \geq 0.4$ medium $(r)>0.6$ strong.

uncoupling between osteoclasts and osteoblasts occurs [13]. Subjects with paraplegia lose bone extremely fast and the SNS is disproportionately involved when compared with the parasympathetic nervous system at highlevel SCI [9]. Clinical evidence exists that the sympathetic regulation of bone does occur in humans and plays a clinically important role in diseases characterized by excessive sympathetic activity [25]. In high-level paraplegia, we can attribute SNS dysfunction after SCI to loss of supraspinal control that occurs with the disruption of spinal cord pathways. In addition, in those with SCI above T6, the clinical sequelae of autonomic dysreflexia appear. We associated group A with significant dysfunction of the SNS (autonomic dysreflexia) as another possible parameter for this statistically significant result.

Wilmet et al. found a 15.1 percent LM reduction in lower limbs 1 year after injury [2]. Maggioni et al. found that the total FM was significantly higher in paraplegics and the LM significantly lower compared with controls [26]. In our study, the subjects with paraplegia had significantly lower LM in the lower limbs. According to the NLOI, FM values in group A and B's lower limbs were increased but not significant compared with group C $(9 \%$ and 28\%, respectively). In high-level paraplegia, impaired or reduced activity of SNS may put paraplegics at a higher risk for developing obesity. Decentralization and impairment of SNS may interrupt the pathway of leptin, described by Jeon et al., and we expected increased FM in group A [13]. However, we found opposite results. This paradoxical finding could possibly be explained as follows: (1) in the chronic injury phase, low-level paraplegics have a similar lifestyle as high-level paraplegics (wheelchair users) and do not use orthoses for lower-limb mobility; (2) some of our subjects with paraplegia were using orthoses to ambulate, so the load and intensity of this locomotion might not be enough to reduce FM in the lower limbs; (3) the role of hormonal mechanisms, particularly leptin, is inadequately explained in paraplegia; and (4) our study did not include the analysis of the paraplegic groups' trunks and total body composition for methodological reasons. This finding needs further investigation but is supported by a strong correlation of DOP with FM in group A's lower limbs, suggesting that this population clearly reflects the neurogenic consequences after SCI.

\section{CONCLUSIONS}

We recognize the possibility of increased mobility using walking orthoses in our study's low-level subjects with paraplegia, which could result in increased energy expenditure and reduced adiposity. The low number of subjects with paraplegia in this study may be considered a limitation; we believe that a similar large-scale study could increase the statistical power of our results. Another study limitation is that the NLOI was at the T12 level or higher in all subjects with paraplegia, with various degrees of spasticity according to the Ashworth Scale. This limitation may have precluded our results regarding the effect of spasticity on bone parameters of the lower limbs.

Table 5.

Parameters measured with dual-energy X-ray absorptiometry in lower limbs of subjects.

\begin{tabular}{lcccc}
\hline Parameter (g) & \multicolumn{3}{c}{ Groups (Mean \pm SD) } & \multicolumn{1}{c}{$\boldsymbol{p}$-Value } \\
\cline { 2 - 4 } & Control $(\boldsymbol{n}=\mathbf{3 3})$ & High-level Paraplegia $(\boldsymbol{n}=\mathbf{1 5})$ & Low-level Paraplegia (n= 15) & 0.001 \\
\hline BMC & $1,213.84 \pm 149.37$ & $898.14 \pm 202.88$ & $873.60 \pm 155.21$ \\
Lean Mass & $19,692.73 \pm 3,242.00$ & $11,739.38 \pm 1,843.39$ & $10,406.33 \pm 2,347.39$ \\
Fat Mass & $6,909.91 \pm 2,497.00$ & $7,552.44 \pm 2,832.65$ & $8,897.53 \pm 3,956.94$ & 0.001 \\
\hline BMC = & &
\end{tabular}

BMC = bone mineral content, SD = standard deviation. 
We must also consider that muscles and bones act as a unit and are related tissues. Therapeutic strategies that help patients with paraplegia bear weight, stand, or walk should be added early in a rehabilitation program to gain muscle and bone benefit.

\section{ACKNOWLEDGMENTS}

\section{Author Contributions:}

Study concept and design: Y. Dionyssiotis. Acquisition, analysis, and interpretation of data: Y. Dionyssiotis. Drafting of manuscript: Y. Dionyssiotis, G. P. Lyritis. Critical revision of manuscript for important intellectual content: G. P. Lyritis, N. Papaioannou, P. Papagelopoulos, T. Thomaides. Study supervision: G. P. Lyritis.

Financial Disclosures: The authors have declared that no competing interests exist.

Funding/Support: This material was unfunded at the time of manuscript preparation.

Additional Information: We would like to thank all subjects with paraplegia and control subjects who took part in this study; Johannes Willnecker and Harald Schubert from Stratec Medizintechnik for their technical advice; Olga Lazoura and Eleni Kourkouveli from the Department of Radiology, National Rehabilitation Center, Athens, Greece, for performing the whole-body DEXA measurements; and Antonios Galonos for performing statistical analysis.

Participant Follow-Up: The authors plan to inform participants of the publication of this study.

\section{REFERENCES}

1. National Spinal Cord Injury Statistical Center. Spinal cord injury: Facts and figures at a glance [Internet]. Birmingham (AL): University of Alabama at Birmingham; 2001 May [cited 2008 Sep]. Available from: http://images.main.uab.edu/ spinalcord/pdffiles/Facts\%2001.pdf/.

2. Wilmet E, Ismail AA, Heilporn A, Welraeds D, Bergmann P. Longitudinal study of the bone mineral content and of soft tissue composition after spinal cord section. Paraplegia. 1995;33(11):674-77. [PMID: 8584304]

3. Biering-Sørensen F, Bohr H, Schaadt O. Bone mineral content of the lumbar spine and lower extremities years after spinal cord lesion. Paraplegia. 1988;26(5):293-301. [PMID: 3205570]

4. Dauty M, Perrouin Verbe B, Maugars Y, Dubois C, Mathe JF. Supralesional and sublesional bone mineral density in spinal cord-injured patients. Bone. 2000;27(2):305-9. [PMID: 10913927] DOI:10.1016/S8756-3282(00)00326-4

5. Dionyssiotis Y, Trovas G, Galanos A, Raptou P, Papaioannou N, Papagelopoulos P, Petropoulou K, Lyritis GP. Bone loss and mechanical properties of tibia in spinal cord injured men. J Musculoskelet Neuronal Interact. 2007;7(1): 62-68. [PMID: 17396008]

6. Clasey JL, Janowiak AL, Gater DR. Relationship between regional bone density measurements and the time since injury in adults with spinal cord injuries. Arch Phys Med Rehabil. 2004;85(1):59-64. [PMID: 14970969] DOI:10.1016/S0003-9993(03)00358-7

7. Eser P, Frotzler A, Zehnder Y, Wick L, Knecht H, Denoth J, Schiessl H. Relationship between the duration of paralysis and bone structure: A pQCT study of spinal cord injured individuals. Bone. 2004;34(5):869-80. [PMID: 15121019] DOI:10.1016/j.bone.2004.01.001

8. Spungen AM, Adkins RH, Stewart CA, Wang J, Pierson RN Jr, Waters RL, Bauman WA. Factors influencing body composition in persons with spinal cord injury: A crosssectional study. J Appl Physiol. 2003;95(6):2398-2407. [PMID: 12909613]

9. Dionyssiotis Y, Petropoulou K, Rapidi CA, Papagelopoulos P, Papaioannou N, Galanos A, Papadaki P, Lyritis GP. Body composition in paraplegic men. J Clin Densitom. 2008;11(3): 437-43. [PMID: 18534884]

DOI:10.1016/j.jocd.2008.04.006

10. Takeda S. Central control of bone remodeling. Biochem Biophys Res Commun. 2005;328(3):697-99. [PMID: 15694403]

11. Karlsson AK, Friberg P, Lönnroth P, Sullivan L, Elam M. Regional sympathetic function in high spinal cord injury during mental stress and autonomic dysreflexia. Brain. 1998;121(9):1711-19. [PMID: 9762959]

DOI:10.1093/brain/121.9.1711

12. Levasseur R, Sabatier JP, Potrel-Burgot C, Lecoq B, Creveuil C, Marcelli C. Sympathetic nervous system as transmitter of mechanical loading in bone. Joint Bone Spine. 2003;70(6):515-19. [PMID: 14756119] DOI:10.1016/j.jbspin.2003.07.006

13. Jeon JY, Steadward RD, Wheeler GD, Bell G, McCargar L, Harber V. Intact sympathetic nervous system is required for leptin effects on resting metabolic rate in people with spinal cord injury. J Clin Endocrinol Metab. 2003;88(1):402-7. [PMID: 12519883] DOI:10.1210/jc.2002-020939

14. Stratec Medizintechnik XCT 3000 manual, software version 5.40. Pforzheim (Germany): Stratec Medizintechnik.

15. Mazess RB, Barden HS, Bisek JP, Hanson J. Dual-energy X-ray absorptiometry for total-body and regional bonemineral and soft-tissue composition. Am J Clin Nut. 1990; 51(6):1106-12. [PMID: 2349926]

16. American Spinal Injury Association. International standards for neurological classification of spinal cord injury. Chicago (IL): American Spinal Injury Association; 2002.

17. Ashworth B. Preliminary trial of carisoprodol in multiple sclerosis. Practitioner. 1964;192:540-42. [PMID: 14143329] 
18. Wilhelm G, Felsenberg D, Bogusch G, Willnecker J, Thaten J, Gummert P. Biomechanical examinations for validation of the bone strength strain index SSI, calculated by peripheral quantitative computed tomography. In: Lyritis GP, editor. Musculoskeletal interactions. Vol. 2. Athens (Greece): Holonome Editions; 1999. p. 108-10.

19. Lehmann LA, Alvarez RE, Macovski A, Brody WR. Generalized image combinations in dual KVP digital radiography. Med Phys. 1981;8(5):659-67. [PMID: 7290019] DOI:10.1118/1.595025

20. Wahner HW, Dunn WL, Brown ML, Morin RL, Riggs BL. Comparison of dual-energy X-ray absorptiometry and dual photon absorptiometry for bone mineral measurements of the lumbar spine. Mayo Clin Proc. 1988;63(11):1075-84. [PMID: 3193817]

21. Health implications of obesity. National Institutes of Health Consensus Development Conference. 11-13 February 1985. Ann Intern Med. 1985;103(2):977-1077. [PMID: 4062129]

22. Bauman WA, Spungen AM, Wang J, Pierson RN Jr, Schwartz E. Continuous loss of bone during chronic immobilization: A monozygotic twin study. Osteoporos Int. 1999;10(2):123-27. [PMID: 10501792] DOI:10.1007/s001980050206
23. Eser P, Frotzler A, Zehnder Y, Denoth J. Fracture threshold in the femur and tibia of people with spinal cord injury as determined by peripheral quantitative computed tomography. Arch Phys Med Rehabil. 2005;86(3):498-504.

[PMID: 15759235]

DOI:10.1016/j.apmr.2004.09.006

24. Frotzler A, Berger M, Knecht H, Eser P. Bone steady-state is established at reduced bone strength after spinal cord injury: A longitudinal study using peripheral quantitative computed tomography (pQCT). Bone. 2008;43(3):549-55. [PMID: 18567554]

DOI:10.1016/j.bone.2008.05.006

25. Schwarzman RJ. New treatments for reflex sympathetic dystrophy. N Engl J Med. 2000;343(9):654-56.

[PMID: 10979798] DOI:10.1056/NEJM200008313430911

26. Maggioni M, Bertoli S, Margonato V, Merati G, Veicsteinas A, Testolin G. Body composition assessment in spinal cord injury subjects. Acta Diabetol. 2003;40(Suppl 1):S183-86. [PMID: 14618468] DOI:10.1007/s00592-003-0061-7

Submitted for publication December 16, 2008. Accepted in revised form June 10, 2009. 